\title{
Integrated system for decision help in urban mobility management - towards sustainable urban area development: VISUTRANS
}

\author{
C. Danoh, A. N'Diaye \& J. Marchal \\ Applied Sciences Faculty, ArGenCo-Anast, \\ University of Liege, Belgium
}

\begin{abstract}
Urban transport problems have become more widespread and severe than ever in both industrialised and developing countries alike. Facing this situation, there is a real need in developing new strategies and innovative tools for transportation and town-planning, as well as economic activities (public or private), within the area. The current tools and systems for solving transport problems are based on using several sub-management tools related to transportation infrastructures, town-planning, road traffic, environmental effects..., which are not sufficiently in interaction. These solutions lead to a severe handicap for urban homogenous and mastered development. That is why the "Urban mobility" has to be rethought. The main idea in this article concerns the development of a multimodal, prospective and flexible tool for the sustainable development of urban areas, which could help the decision makers in urban transportation fields.
\end{abstract}

Keywords: integrated transportation planning, transportation data model, transport modelling, decision help, and sustainable development.

\section{Introduction}

Urban transport problems have become more widespread and severe (Ortuzar and Willumsen [24]). The old problems, such as congestion, pollution accidents and financial deficits, are now coupled with land use and environmental problems. This situation reduces significantly the effectiveness of the transport system. Thus, several researches have been undertaken in order to solve them. Therefore, the problems still grow and the planning methodologies developed in 
recent decades do not efficiently change the circumstances into a sustainable situation. In this context, contemporary transport planning requires a new philosophy in terms of tools and strategies, skilled professionals and modelling techniques with implementations in software (Ortuzar and Willumsen [24]). Furthermore, Kauffmann [16] mentioned that urban transport is characterized by multidimensional aspects, which present key indications for properly handling urban transport problems.

It is in this framework that the following article proposes an innovative and integrated system that aims to assist the decision makers in choosing appropriate solutions related to urban mobility.

The approach undertaken in this article will first of all analyze recent developments in transport planning and their impacts on urban mobility. Then, based on this analysis, a data model will be proposed in order to provide a new conceptual and comprehensive urban mobility management tool for a sustainable urban development.

\section{Analysis of recent researches}

The transport planning might be a comprehensive process with the collection, analysis and interpretation of relevant data concerned with existing situation (Banister et al. [1]). One of the basic structures of the transport planning has been developed by Thomson [27]: Problem Identification; Diagnosis; Projection; Constraints; Options; Formulation of plans; testing of alternatives and Evaluation.

As a strategy tool for planning, the transport planning model (TPM) is the central part of transport planning process and essential for generating and testing alternatives. Variations of the basic format coupled with TPM have been applied and carried out all over the world (Banister et al. [1]). Therefore, transport problems still appear. The optimal solutions seem to be found by the integration of land use, environmental criteria and all the disciplines involved in urban transport planning process (Meyer and Miller [21]).

This new philosophy allowed the development of integrated and interactive transport planning strategies and tools which aims to contain and master urban transport problems all over most important cities in the world. Thus, integrated plans have been developed; taking generally in account land use, enhance public transport policy, traffic calming in residential and city-centres locations, road pricing, environment caution...

Moreover, several multimodal transport planning software have been developed in regard to integrated plans, INRETS [15]: Emme 2/3 (Canada), Polydrom (Switzerland), TP+/ VIPER (USA), TRIPS (Great Britain) VISEM/DAVISUM (France-Germany)... The evolution of transport planning process (plans + models) brings more robustness to solutions for better handling urban transport problems.

Despite these advanced, the tools developed are not enough correlated and interactions between key elements for solving urban transport problems are weakly undertaken. Moreover, those elements are often used separately while 
urban mobility appears as a multidisciplinary phenomenon (Kauffman [16]). Town planners, urban and transport (goods and persons) agencies, public transport operators, economists, experts in external transport effects assessment contribute individually in the improvement of urban transport efficiency. Doing so, each decision maker has not really a global view of the given situation in order to provide an optimum decision. This way of dealing with urban transport problems leads to a severe handicap for sustainable development for urban areas.

So, the renewed idea is to consider the traffic models developed above, as a part of a whole system where, the other transport aspects (noise, pollution, activities location, economic impact...) can be link to generate optimal solutions for transport problem.

That is why the idea developed in this paper proposes a system where urban transport decision-makers will dispose of all data and information related to the whole urban transport system before developing strategies and policies in regard to transport problems.

The idea is to develop an Intelligent Data Base (IDB) that is able to link the Traffic Model, Noise Model, Pollution Model, Economic Model and Optimal socio-economic Activities location by using existing efficient models and by using the plug and play technology. This vision leads to the development of integrated scenarios necessary for solving current urban transport problem. The IDB may also contain quantitative and qualitative data for monitoring the transport systems, in terms of road level of service, public transport management, socio-economic characteristics and location.

The following paragraph deals with the theoretical framework of integrated transport before demonstrating the feasibility of an integrated system for urban transport management.

\section{Integrated system for decision help in urban mobility management}

Transport is essential for any socio-economic activity: goods transport, work, school, leisure, relationship... More accessibilities and better level of transport services and life quality are key factors for development. Facing severe urban transport problem and having in mind the improvement of households and goods trip conditions, transport decision makers need to be assist with innovative, efficient and relevant management tolls. As we argued above, urban mobility appears as a multidisciplinary phenomenon: traffic engineering, urban planning, public transports, socio-economic and environmental factors, sociological aspects... Thus, optimal and adequate solutions for urban transport problems need an integrated and transversal vision trough the whole urban system.

The approach to undertake transportation interest may arise from an integrated transportation planning (Meyer and Miller [21]), coupled with real decision help tool.

The idea here is to develop an integrated transport planning system which will be able to support quantitative and qualitative analysis and evaluation of contemplated changes in the Urban System. The system will also help users for 
monitoring and analyzing the existing traffic conditions, forecasting the effects of projected strategies, estimating parameters for traffic models, validating the performance of traffic models for planning, appreciating the impacts of each alternative (European Commission [12], Taylor and Young [26], Ortuzar and Willumsen [24], Bonnel [6]) have identified the importance of transport data for any kind of transport planning process. That explains why the integrated system in interest will first of all need a theoretical framework base on a specific data model (MIDAM) which will provide the feasibility of the integrated system for decision help in urban transport analysis (VISUTRANS).

\subsection{Data model MIDAM}

The conception and development of a transport planning tool need a data model which expresses its philosophy approach. The data model adopted in this paper concerns the data related to the whole urban system and not only set on traffic data: the socio-economic organization, the network structure, transport modes used for trips and exogenous data extract form extern models such as noise and pollution model, economic model or traffic management model.

The integration of all this data, which are not used in this way before, allows decision makers to better appreciate the impacts of any kind of alternative or scenario to be developed.

The data used in MIDAM are the following:

- Socio-economic data characteristics and locations. Urban traffic is a function of land use. If land use could be controlled, then the origins and destinations of journeys could be determined. Socio-economic activities are identified by zone which is modelling by using centroid.

- Transportation network data depicts transport infrastructures and the means of traffic management

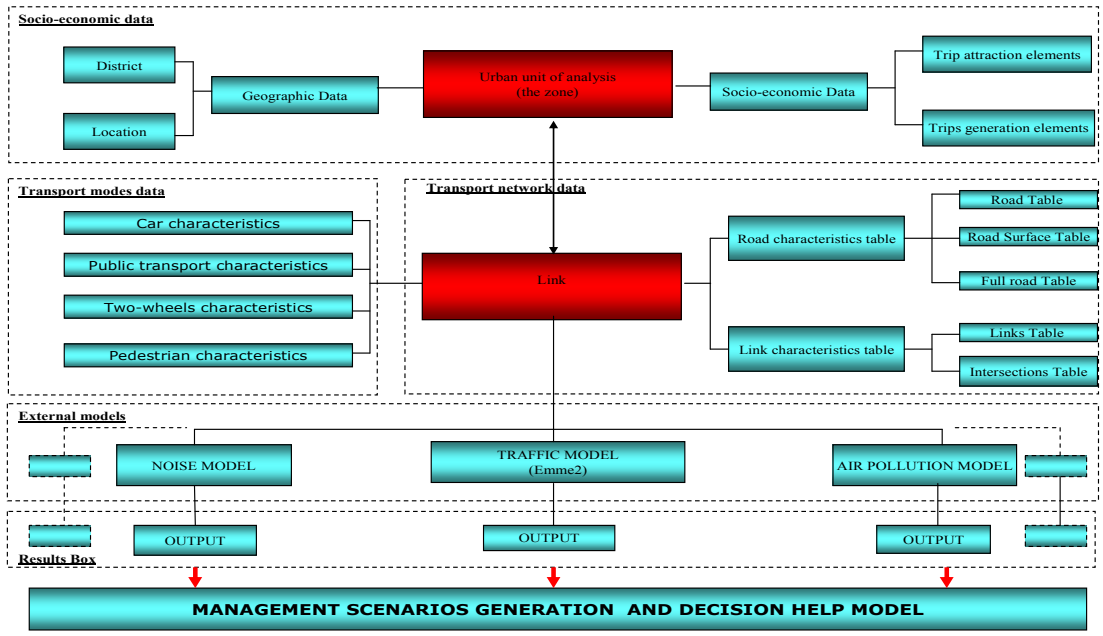

Figure 1: Integrated data model for urban transport management: MIDAM. 
- Transport modes characterise the various transport modes available on the urban study area

- External models deal with Traffic model such as Emme2, noise model, pollution model, economic model...

- Results box represents results from external models, which can be used as input for other models. For example, Results Box can contain travel flow from traffic model which could be used as input for external transport effects.

The figure 1 shows the data model scheme: MIDAM.

\subsection{Key issues from MIDAM}

From this data model, five main points are depicted below:

- Zone depicts socio-economic unit of analysis. Generation and attraction elements are necessary to handle flow amount and patterns.

- Link characterises transport impact unit of analysis. For example, in the case of congested road, the pollution will be differently appreciate if there are or not habitations around the roadway. The same analysis could be undertaken to analyse the supply of road parking along the roadway - possibility to enlarge the road and/or build sidewalk...

- Relations between link and zone characterise by the duality between transport and land use. The accessibility level is strongly associated with the transport service quality level.

- Integrated and multimodal data model by taking into account existing model involve in transportation field, all the modes available on the study area, socio-economical and environmental aspects, the transport model develop here bring an optimal response to urban transport problems.

- Real decisions help tool for urban transport management by integrating the data model to an assessment and evaluation system in order to assist urban transport decision makers.

The data model describes above, satisfies the framework concerning integrated and adequate way to better handle urban mobility problems. Furthermore, in regard to MIDAM, a demonstration has been done to prove the feasibility of such a relevant transport planning system.

\subsection{Design of an integrated system for decision help in urban mobility management}

Based on the data model MIDAM, a demonstration tool, VISUTRANS, has been developed by using MS Access and Matlab programming tools. The overview of VISUTRANS is shown in figure 2. Nowadays urban mobility problems require contemporary transport planning such as VISUTRANS. The inputs concern urban and transport data. Land use is considered in the concept as well as external transport impacts and assessment tools. 


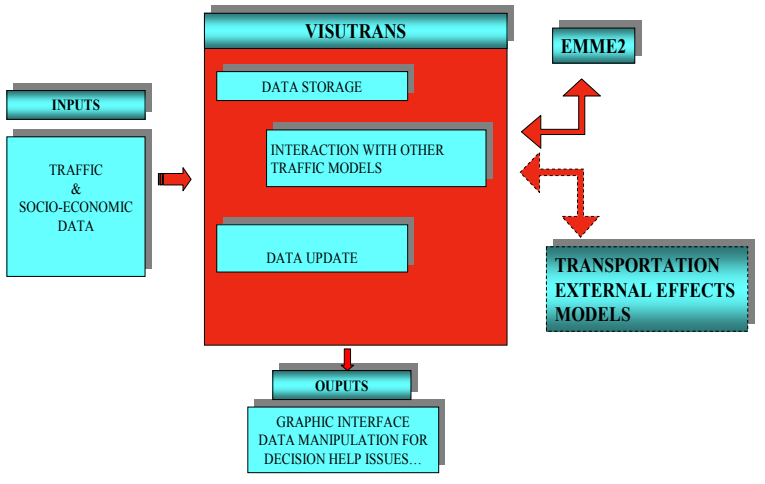

Figure 2: Overview of VISUTRANS.

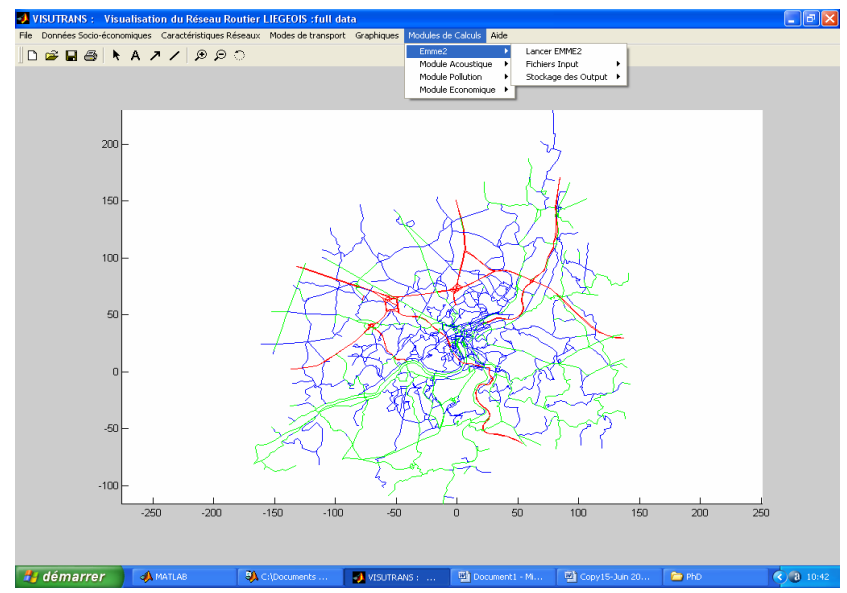

Figure 3: Integration illustration.

The outputs present graphical interface with integrated, multimodal and environmental lay out. Its assessment tool provides a real assistance for urban transport decision-makers. VISUTRANS presents several characteristics:

- Prospective tool: Socio-economic data manipulation for creating scenarios; state of the road and highway network, road description and drawn, links characteristics;

- Integrated tool: External transport models to our system such as traffic model, assessment model, pollution and noise estimation model... are linked to VISUTRANS data base by plug and play technology;

- Multimodal tool: private vehicles, public transport mode, two-wheels and pedestrians are taken into account by VISUTRANS. 


\subsection{VISUTRANS illustrations}

The graphic interface offers many possibilities to the users during the planning process and the decision making. Some illustrations of the integrated System for Decision Help in Urban Mobility Management are described below.

Illustration 1: Integrated tool

This illustration depicts the interaction between VISUTRANS data base and traffic, air, pollution and economic models.

\section{Illustration 2: Multimodal tool}

The figure below illustrates the consideration of all the modes available in an urban area. Intermodality can be studied to improve the transport system.

Illustration 3: Transit lines management

Figure 5 shows the opportunity to manage all kind of transit line. Number and type of lines by zone, headways, frequencies, fuel consumption, road occupancy...

Illustration 4: Prospective tool

Figure 6 depicts the possibilities to monitor, analyse, and modify the existing socio-economic properties, road networks, transport mode in order to master and contain urban mobility development.

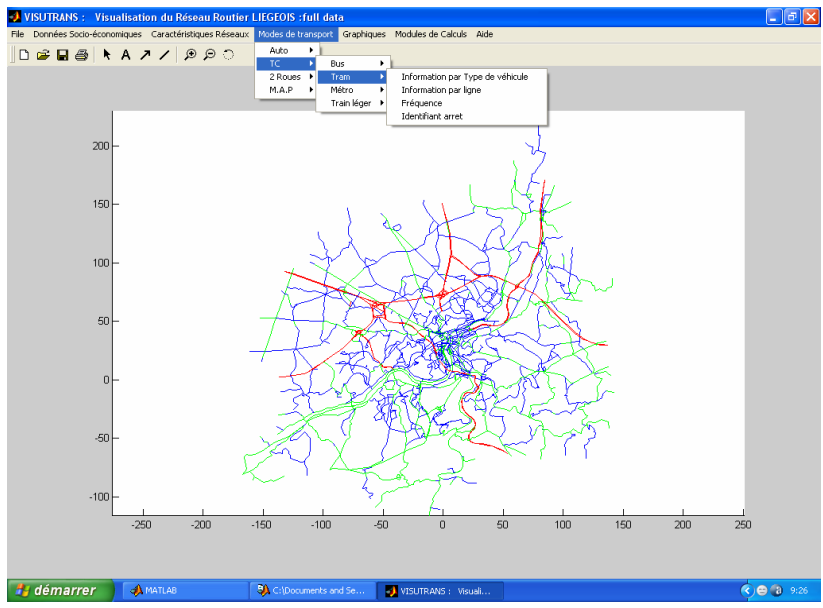

Figure 4: Multimodality illustration. 


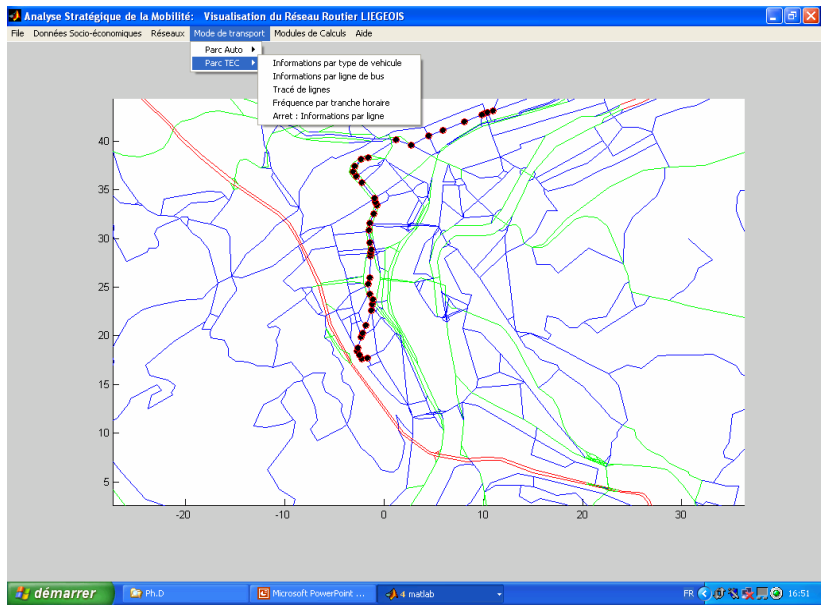

Figure 5: $\quad$ Transit lines management.

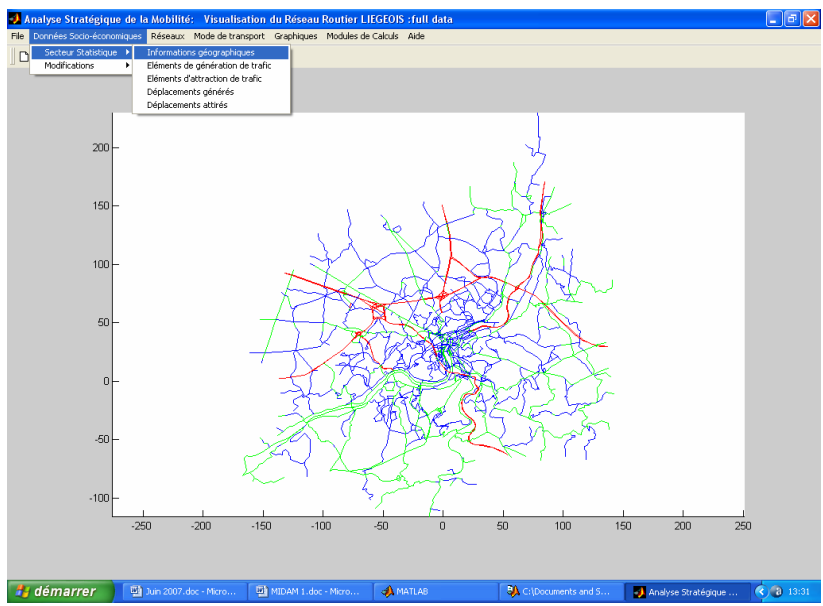

Figure 6: $\quad$ Prospective illustration.

\section{Conclusion}

Contemporary transport planning tools require renewed theoretical framework. The decision - makers have to be aware of each alternative or scenario impacts on the whole urban system in order to contribute to a sustainable development. By elaborating an integrated system for decision help in urban transport management, there is an opportunity to let the decision-makers to have an overview of the urban system. Service quality on road networks, cars patterns, public transport, urban planning, goods transport, environmental aspects are essential for transport planning issues. VISUTRANS, which is characterised by 
this transversal and integrated issue for transport planning, represents a real tool for assisting urban transport decision makers. Its assessment tool, multimodal, integrated and prospective aspects are key components to better handle urban mobility problems. Tools like VISUTRANS are intended for municipalities, urban development agencies, public transport planners and engineering consulting firms in transport.

\section{References}

[1] Banister, D., Nijkamp, P. \& Priemus, H., "Mobility and spatial dynamics: an uneasy relationship”, In Journal of transport geography, $\mathrm{n}^{\circ}$ 9, 2001.

[2] Baye, E. \& Debizet, G., Des nouvelles problématiques urbaines à l'innovation de l'expertise transport / déplacement: Mise en parallèle et convergence : Allemagne - France - Royaume Uni, Prédit 1996-2000, Economie et Humanisme, Cerat, 166 p., 2001.

[3] Ben-Akiva, M. \& Lerman, S.R., "Discrete choice analysis: Theory and application to travel demand", The MIT Press Cambridge, Massachusetts London, England, 1985.

[4] Ben-Akiva, M., Mc Fadden, D., Train, K., Choice Models: Progress and Challenges, Working paper, Mannheim Research Institute for the Economics of Aging (MEA), 2002.

[5] Bonnel, P. \& Zhang, C., Définition d'une typologie de la mobilité adaptée à la modélisation de la demande, Lyon, ISIS et LET, 85 p, 2001.

[6] Bonnel, P., Prévoir la demande de transports, Presses de l'Ecole Nationale des Ponts et Chaussées, Paris, 2004.

[7] Bonnafous, A., Patier-Marquec, D. \& Plassard, F., Mobilité' et vie quotidienne, Lyon, Presses Universitaires de Lyon, coll. Transport, espace, société, $172 \mathrm{p}, 1981$.

[8] Cancalon, F. \& Gargaillo, L., Les Transports Collectifs Urbains: Quelles méthodes pour quelles stratégies?, Editions Celse, Paris, 1991.

[9] CEMT (Conseil européen des ministres des transports) et OCDE (Organisation de coopération et de développement économique), Transports urbains et développement durable. Paris: CEMT et OCDE, 268 p, 1995.

[10] Chung, J-H., Viswanathan, Kr., Goulias, K. (), Design of Automatic Comprehensive Traffic Data Management System for Pennsylvania, Transportation Research Record $n^{\circ}$ 1625, TRB, National Academic Press, Washington DC, pp 1-11, 1998.

[11] Dueker, K. J. \& Butler, J. A. (), GIS-T enterprise data model with suggested implementation choices, Discussion paper, Center for Urban Studies, Portland State University, 1997.

[12] European Commission, Green Paper, Towards a new culture for urban mobility, European Commission, 2007.

[13] Fletcher, D., Geographic information systems for transportation: A look forward, in Transportation in the New Millenium: State of the Art and Future Directions, Washington, DC: Transportation Research Board, 2000. 
[14] Harvey, J. M. \& Shih-Lung, S., Geographic Information Systems for Transportation: Principles and Applications, Oxford University Press, 480p, 2001.

[15] INRETS (Institut National de Recherche sur les transports et leur sécurité, France), Intermodalité: Bilanet Perspectives des Systèmes informatiques, Rapport de Convention DTT, 2002.

[16] Kaufmann, V., Mobilité et vie quotidienne: synthèse et questions de recherche, Centre de prospective et de veille scientifique, Paris: Ministère de l’Équipement, des Transports et du Logement, 2001 Plus n48, 1999.

[17] Kaufmann, V., «Mobilité quotidienne et dynamiques urbaines: la question $d u$ report modal», Presses polytechniques et Universitaires Romandes, Lausanne, 252p, 2000.

[18] Masson, S., Les interactions entre système de transport et système de localisation en milieu urbain et leur modélisation, Thèse de doctorat, Université Lumière Lyon 2, France, 2000.

[19] Merlin, P., La planification des transports urbains, Enjeux et Méthodes, Masson, Paris, 220p, 1984.

[20] Merlin, P., Les Politiques de transport urbain, La Documentation française, 1985.

[21] Meyer, M., Miller, E., Urban Transportation Planning, Second Edition, McGraw-Hill series in Transportation, 2001.

[22] N'Diaye, A. B., De l'analyse du choix discret en général et du LOGIT multinomial en particulier, Département d'Analyse des Systèmes de Transport, Université de Liége, Editions ANAST, 1994.

[23] Newman, P. \& Kenworthy, W., Sustainability and cities. Overcoming automobile dependence. Washington: Island Press, p. 193, 1999.

[24] Ortuzar, J. D. \& Willumsen, L., Modelling Transport, Third Edition, John Willey \& Sons LTD, 2001.

[25] Sheffi, Y., Urban Transportation Networks: Equilibrium Analysis with Mathematical Programming Methods, Prentice-Hall, 1985.

[26] Taylor, M. \& Young, W., Understanding Traffic Systems, Data analysis and Presentation, Avebury Technical, 1996.

[27] Thomson, J.M., Modern Transport Economics, Harmondsworth, Penguin, 1974. 